\title{
ANALISIS PENGARUH DIMENSI PELAYANAN PRIMA TERHADAP KEPUASAN NASABAH TABUNGAN BRI KABTOR CABANG KENDAL
}

\author{
Ayu Rosefiani Syara*) \\ Jati Handayani**) \\ *)ayurosefiani07@gmail.com
}

\begin{abstract}
This study aims to determine the dimensions of service excellence consists of ability, attitude, appearance, attention, action, and accountability toward Customer Satisfaction Savings at PT Bank Rakyat Indonesia (Persero) Tbk. Branch Office Kendal.

Testing method of data that used in this study was to test the validity, reliability test, normality test, multicoloniarity, test heteroskedastisitas, autocorrelation test, test analysis linear multiple, $F$ test, $t$ test, and test the coefficient of determination $\left(R^{2}\right)$ which shows the can used to measure customer satisfaction savings.

Multiple linear regression method yields customer satisfaction equation $=-0,937+$ 0,346 Ability + 0.226Attitude + 0.179Appearance +0.207 Attention + 0,381Action + $0,294 A$ ccountability $+e$. In $F$ test, it is found that the dimensions of service excellence Ability, Attitude, Appearance, Attention, Action, and Accountability simultaneously have significant influence to Customer Satisfaction Savings at PT Bank Rakyat Indonesia (Persero) Tbk. Branch Office Kendal. The result of t test is influence Ability, Attitude, Appearance, Attention Action, and Accountability have significant influence to Customer Satisfaction Savings at PT Bank Rakyat Indonesia (Persero) Tbk. Branch Office Kendal.
\end{abstract}

Keywords: Dimensions of Service Excellence; Customer Satisfaction

*) Mahasiswa Tugas Akhir Prodi Keuangan dan Perbankan, Jurusan Akuntansi, Politeknik Negeri Semarang

**) Dosen Jurusan Akuntansi Politeknik Negeri Semarang

\section{PENDAHULUAN}

Perkembangan perekonomian Indonesia saat ini khususnya dalam sektor jasa menciptakan sebuah persaingan yang ketat tidak terkecuali pada sektor perbankan. Sektor perbankan merupakan salah satu bidang yang harus mempertahankan eksistensinya sebagai lembaga keuangan dalam perekonomian. Dewasa ini perkembangan di bidang perbankan dari tahun ke tahun berkembang dengan pesat. Hal tersebut menimbulkan persaingan yang ketat antara bank yang satu dengan bank yang lainnya. Dengan persaingan yang ketat, maka semua bank akan memberikan kualitas pelayanan yang baik untuk mendapatkan calon nasabah. Hal tersebut diharapkan agar pihak bank dapat menciptakan kepuasan nasabah terhadap kualitas layanan yang telah diberikan pihak perbankan kepada para nasabah.

Definisi pelayanan prima (service excellence) adalah kepedulian kepada pelanggan dengan memberikan layanan terbaik untuk memfasilitasi kemudahan pemenuhan kebutuhan dan mewujudkan kepuasannya, agar mereka selalu loyal kepada organisasi atau perusahaan (Barata, 2003:27). Pelayanan nasabah yang bermutu menuntut adanya upaya keseluruhan karyawan bukan hanya karyawan yang bertugas di front office yang berhadapan langsung 
dengan nasabah dalam menghasilkan pelayanan yang mencerminkan kualitas, tetapi juga karyawan yang bertugas di back office yang menghasilkan pelayanan di belakang layar yang tidak kelihatan oleh nasabah.

Berdasarkan hasil survei Bank Service Excellence Monitor (BSEM), yang dilakukan oleh Marketing Research Indonesia (MRI) bekerja sama dengan Majalah Infobank periode Mei 2018, mengenai hasil 10 Bank Terbaik dalam Pelayanan Prima Tahun 2017-2018 dapat dilihat pada Tabel 1 berikut

Tabel 1 Indeks 10 Bank Terbaik dalam Pelayanan Prima 2017-2018

\begin{tabular}{|c|l|c|c|l|l|}
\hline \multicolumn{3}{|c|}{ Tahun 2017 } & \multicolumn{3}{c|}{ Tahun 2018 } \\
\hline Peringkat & Nama Bank & $\begin{array}{c}\text { Indeks } \\
(\mathbf{\%})\end{array}$ & Peringkat & Nama Bank & $\begin{array}{c}\text { Indeks } \\
(\%)\end{array}$ \\
\hline 1 & Mandiri & 83,81 & 1 & $\begin{array}{l}\text { Commonwealth } \\
\text { Bank }\end{array}$ & 84,51 \\
\hline 2 & Permata Bank & 82,38 & 2 & Danamon & 82,53 \\
\hline 3 & Danamon & 78,53 & 3 & Permata Bank & 82,09 \\
\hline 4 & BNI & 78,16 & 4 & BNI & 81,13 \\
\hline 5 & BCA & 71,03 & 5 & BCA & 74,63 \\
\hline 6 & $\begin{array}{l}\text { Commonwealth } \\
\text { Bank }\end{array}$ & 70,03 & 6 & BTN & 72,00 \\
\hline 7 & BTN & 69,39 & 7 & Mandiri & 71,65 \\
\hline $\mathbf{8}$ & BRI & $\mathbf{6 8 , 3 3}$ & 8 & Maybank & 71,01 \\
\hline 9 & Maybank & 67,46 & 9 & CIMB Niaga & 70,66 \\
\hline 10 & CIMB Niaga & 67,07 & $\mathbf{1 0}$ & BRI & $\mathbf{7 0 , 2 2}$ \\
\hline
\end{tabular}

Sumber : Majalah Infobank edisi bulan Mei, 2018 (data diolah:2019)

Berdasarkan Tabel 1 menunjukkan bahwa pelayanan prima pada PT Bank Rakyat Indonesia (Persero) Tbk. mengalami penurunan peringkat dari tahun 2017 ke tahun 2018. Pada tahun 2017 PT Bank Rakyat Indonesia (Persero) Tbk. menduduki peringkat ke 8 dengan persentase 68,33\%. Sedangkan pada tahun 2018 mengalami penurunan peringkat dengan menduduki peringkat ke 10 meskipun persentasenya meningkat menjadi 70,22\%. Dengan menurunnya peringkat pelayanan prima tersebut diharapkan PT Bank Rakyat Indonesia (Persero) Tbk. mampu meningkatkan performa pelayanan prima dan mampu bersaing dengan bank lain.

Berdasarkan data di atas, maka rumusan masalah dalam penelitian ini adalah bagaimanakah meningkatkan dimensi pelayanan prima (service excellence) terhadap kepuasan nasabah tabungan. Hal tersebut dapat dilakukan dengan mengetahui pengaruh ability, attitude, appearance, attention, action, dan accountability terhadap kepuasan nasabah tabungan. Berdasarkan uraian di atas penelitian ini difokuskan pada "Analisis Pengaruh Dimensi Pelayanan Prima Terhadap Kepuasan Nasabah Tabungan pada PT Bank Rakyat Indonesia (Persero) Tbk. Kantor Cabang Kendal". 


\section{TINJAUAN LITERATUR}

\section{Pelayanan Prima (Service Excellence)}

Pelayanan prima (service excellence) adalah kepedulian kepada pelanggan dengan memberikan layanan terbaik untuk memfasilitasi kemudahan pemenuhan kebutuhan dan mewujudkan kepuasannya, agar nasabah loyal kepada perusahaan (Barata, 2003:27).

\section{Kepuasan Nasabah}

Menurut Kotler (1997:40) dalam Rangkuti (2003:23) mendefinisikan kepuasan pelanggan atau nasabah adalah perasaan senang atau kecewa seseorang sebagai hasil dari perbandingan antara prestasi atau produk yang dirasakan dan yang diharapkan. Indikator pada variabel kepuasan ini merujuk pada Jurnal Fadilah, Yesi N et al (2013), yang dikembangkan pada penelitian ini, yaitu sebagai berikut:

$\mathrm{Y}_{1.1}$ : Saya puas dengan kemampuan karyawan.

$\mathrm{Y}_{1.2}$ : Saya puas dengan sikap karyawan.

$\mathrm{Y}_{1.3}$ : Saya puas dengan penampilan karyawan.

$\mathrm{Y}_{1.4}$ : Saya puas dengan perhatian karyawan.

$\mathrm{Y}_{1.5}$ : Saya puas dengan tindakan karyawan.

$\mathrm{Y}_{1.6}$ : Saya puas dengan tanggung jawab karyawan.

\section{Kemampuan (Ability)}

Kemampuan atau ability adalah pengetahuan dan keterampilan tertentu yang mutlak diperlukan untuk menunjang program layanan prima, yang meliputi kemampuan dalam bidang kerja yang ditekuni, melaksanakan komunikasi yang efektif, mengembangkan motivasi, dan menggunakan public relations sebagai instrumen dalam membina hubungan ke dalam dan ke luar organisasi atau perusahaan (Barata, 2003:31). Indikator pada dimensi ini merujuk pada Jurnal Fadilah, Yesi N et al (2013), yang dikembangkan dalam penelitian ini, yaitu sebagai berikut :

$\mathrm{X}_{1.1}$ : Saya puas dengan kemampuan karyawan dalam melayani nasabah.

$\mathrm{X}_{1.2}$ : Saya puas dengan kemampuan karyawan dalam berkomunikasi dengan nasabah.

$\mathrm{X}_{1.3}$ : Saya puas dengan kemampuan karyawan dalam menjaga hubungan baik dengan nasabah.

\section{Sikap (Attitude)}

Sikap atau attitude adalah perilaku atau perangai yang harus ditonjolkan ketika menghadapi pelanggan (Barata, 2003:31). Indikator pada dimensi ini merujuk pada Jurnal Fadilah, Yesi N et al (2013), yang dikembangkan dalam penelitian ini, yaitu sebagai berikut : $\mathrm{X}_{2.1}$ : Saya puas dengan sikap ramah karyawan terhadap nasabah. 
$\mathrm{X}_{2.2}$ : Saya puas dengan sikap sopan karyawan terhadap nasabah.

$\mathrm{X}_{2.3}$ : Saya puas dengan sikap sabar karyawan terhadap nasabah.

$\mathrm{X}_{2.4}$ : Saya puas dengan sikap menghormati yang ditunjukkan karyawan terhadap nasabah.

\section{Penampilan (Appearance)}

Penampilan atau appearance adalah penampilan seseorang, baik yang bersifat fisik dan non fisik, yang mampu merefleksikan kepercayaan diri dan kredibilitas dari pihak lain (Barata, 2003:31) Indikator pada dimensi ini merujuk pada Jurnal Fadilah, Yesi N et al (2013), yang dikembangkan dalam penelitian ini, yaitu sebagai berikut :

$\mathrm{X}_{3.1}$ : Saya puas dengan penampilan karyawan yang menarik saat bekerja.

$\mathrm{X}_{3.2}$ : Saya puas dengan penampilan karyawan yang serasi atau seragam saat bekerja.

$\mathrm{X}_{3.3}$ : Saya puas dengan penampilan karyawan yang rapi dan bersih saat bekerja.

$\mathrm{X}_{3.4}$ : Saya puas dengan penampilan karyawan yang sesuai dengan etika saat bekerja.

\section{Perhatian (Attention)}

Perhatian atau attention adalah kepedulian penuh terhadap pelanggan baik yang berkaitan dengan perhatian akan kebutuhan dan keinginan pelanggan maupun pemahaman atas saran dan kritiknya (Barata, 2003:31). Indikator pada dimensi ini merujuk pada Jurnal Fadilah, Yesi $\mathrm{N}$ et al (2013), yang dikembangkan dalam penelitian ini, yaitu sebagai berikut :

$\mathrm{X}_{4.1}$ : Saya puas dengan perhatian karyawan dalam mengatasi kebutuhan yang dialami oleh nasabah.

$\mathrm{X}_{4.2}$ : Saya puas dengan perhatian karyawan yang luwes dalam membimbing nasabah.

$\mathrm{X}_{4.3}$ : Saya puas dengan perhatian karyawan yang selalu bersedia meluangkan waktu menanggapi permintaan nasabah.

$\mathrm{X}_{4.4}$ : Saya puas dengan perhatian karyawan dalam menerima saran yang diberikan nasabah.

$\mathrm{X}_{4.5}$ : Saya puas dengan perhatian karyawan dalam menerima kritik yang diberikan nasabah.

\section{Tindakan (Action)}

Tindakan atau action adalah berbagai kegiatan nyata yang harus dilakukan dalam memberikan layanan kepada pelanggan (Barata, 2003:31). Indikator pada dimensi ini merujuk pada Jurnal Fadilah, Yesi N et al (2013), yang dikembangkan dalam penelitian ini, yaitu sebagai berikut :

$\mathrm{X}_{5.1}$ : Saya puas dengan tindakan karyawan dalam merespon keluhan yang disampaikan nasabah.

$\mathrm{X}_{5.2}$ : Saya puas dengan tindakan karyawan yang bekerja dengan teliti.

$\mathrm{X}_{5.3}$ : Saya puas dengan tindakan karyawan dalam memberikan layanan dengan cepat kepada nasabah. 
$\mathrm{X}_{5.4}$ : Saya puas dengan tindakan karyawan dalam memberikan informasi terbaru kepada nasabah.

\section{Tanggung jawab (Accountability)}

Tanggung jawab atau accountability adalah suatu sikap keberpihakan kepada pelanggan sebagai wujud kepedulian untuk menghindarkan atau meminimalkan kerugian atau ketidakpuasan pelanggan (Barata, 2003:31). Indikator pada dimensi ini merujuk pada Jurnal Fadilah, Yesi $\mathrm{N}$ et al (2013), yang dikembangkan dalam penelitian ini, yaitu sebagai berikut : $\mathrm{X}_{6.1}$ : Saya puas dengan tanggung jawab karyawan dalam memberikan solusi atas permasalahan yang dihadapi oleh nasabah.

$\mathrm{X}_{6.2}$ : Saya puas dengan tanggung jawab karyawan dalam memberikan kemudahan prosedur pelayanan kepada nasabah.

$\mathrm{X}_{6.3}$ : Saya puas dengan tanggung jawab karyawan yang berusaha untuk tidak melakukan kesalahan kepada nasabah.

$\mathrm{X}_{6.4}$ : Saya puas dengan tanggung jawab karyawan dalam menyelesaikan keluhan yang dihadapi oleh nasabah.

\section{Kerangka Pemikiran Teoritis}

Kerangka pemikiran teoritis pada penelitian ini terlihat pada Gambar 1.

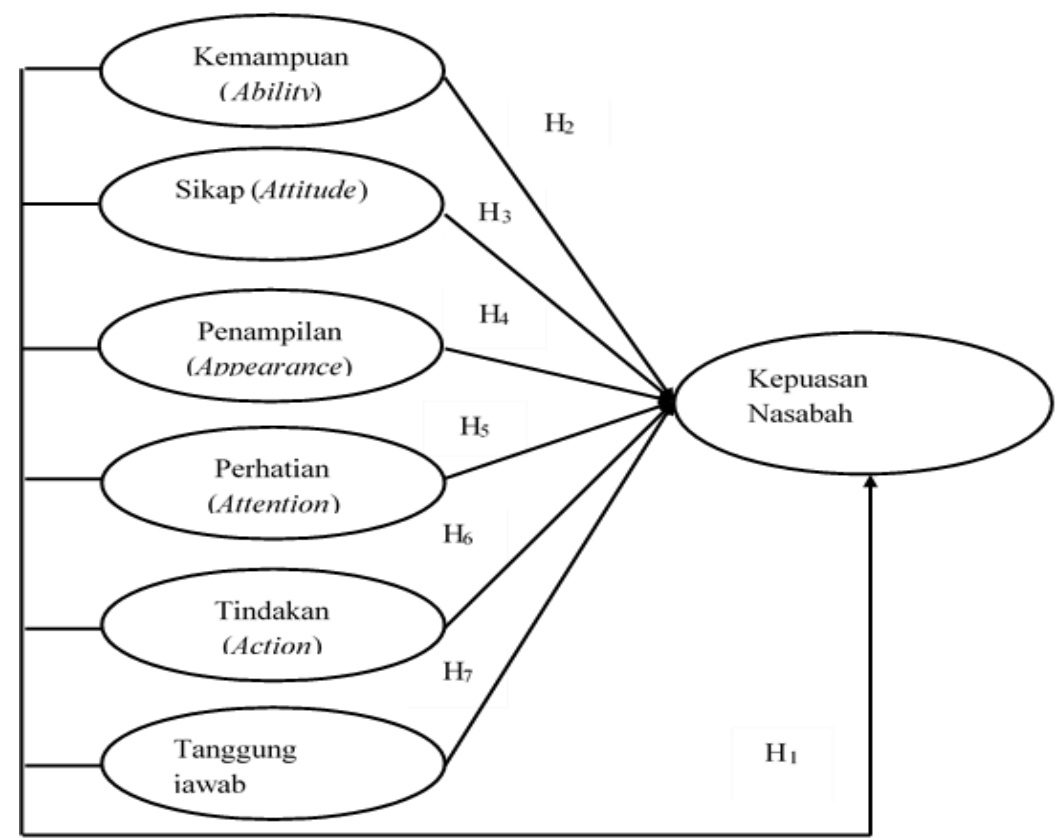

Sumber : Penelitian terdahulu yang telah diolah kembali.

\section{Hipotesis Penelitian}

\section{Gambar 1 Kerangka Pemikiran Teoritis}

H1: Diduga bahwa pelayanan prima yang meliputi kemampuan (ability), sikap (attitude), penampilan (appearance), perhatian (attention), tindakan (action), dan tanggung jawab 
(accountability), secara simultan mempunyai pengaruh yang signifikan terhadap kepuasan nasabah tabungan pada PT Bank Rakyat Indonesia (Persero) Tbk. Kantor Cabang Kendal.

H2: Diduga bahwa variabel kemampuan (ability) secara parsial mempunyai pengaruh yang signifikan terhadap kepuasan nasabah tabungan pada PT Bank Rakyat Indonesia (Persero) Tbk. Kantor Cabang Kendal.

H3: Diduga bahwa variabel sikap (attitude) secara parsial mempunyai pengaruh yang signifikan terhadap kepuasan nasabah tabungan pada PT Bank Rakyat Indonesia (Persero) Tbk. Kantor Cabang Kendal.

H4: Diduga bahwa variabel penampilan (appearance) secara parsial mempunyai pengaruh yang signifikan terhadap kepuasan nasabah tabungan pada PT Bank Rakyat Indonesia (Persero) Tbk. Kantor Cabang Kendal.

H5: Diduga bahwa variabel perhatian (attention) secara parsial mempunyai pengaruh yang signifikan terhadap kepuasan nasabah tabungan pada PT Bank Rakyat Indonesia (Persero) Tbk. Kantor Cabang Kendal.

H6: Diduga bahwa variabel tindakan (action) secara parsial mempunyai pengaruh yang signifikan terhadap kepuasan nasabah tabungan pada PT Bank Rakyat Indonesia (Persero) Tbk. Kantor Cabang Kendal.

H7: Diduga bahwa variabel tanggung jawab (accountability) secara parsial mempunyai pengaruh yang signifikan terhadap kepuasan nasabah tabungan pada PT Bank Rakyat Indonesia (Persero) Tbk. Kantor Cabang Kendal.

\section{METODOLOGI PENELITIAN}

Tipe penelitian yang digunakan adalah penelitian kausal. Penelitian kausalitas diarahkan untuk menggambarkan adanya hubungan sebab akibat antara beberapa situasi yang digambarkan dalam variabel dan atas dasar itulah kemudan akan ditarik kesimpulan umum (Ferdinand, 2006:4).

Populasi dalam penelitian ini yaitu seluruh nasabah tabungan pada PT Bank Rakyat Indonesia (Persero) Tbk. Kantor Cabang Kendal. Jumlah sampel sebanyak 100 responden. Teknik pengambilan sampel menggunakan purposive sampling.

Instrumen penelitian dalam penelitian ini menggunakan kuesioner dengan pertanyaan terbuka dan pertanyaan tertutup menggunakan skala likert mulai dari Sangat Tidak Setuju (STS), Tidak Setuju (TS), Setuju (S), dan Sangat Setuju (SS). Teknik analisis dengan menggunakan bantuan program software SPSS 20 yang terdiri dari Uji Instrumen Penelitian 
(Uji Validitas dan Uji Reliabilitas), Uji Asumsi Klasik (Uji Normalitas, Uji Multikolonieritas, Uji Heteroskedastisitas, dan Uji Autokorelasi), dan Uji Regresi Linear Berganda (Uji F, Uji t, dan $\mathrm{Uji} \mathrm{R}^{2}$ ).

\section{HASIL DAN PEMBAHASAN}

\section{Uji Validitas}

Hasil uji validitas menunjukkan bahwa $\mathrm{r}_{\text {hitung }}$ dari semua indikator lebih besar dari $\mathrm{r}_{\text {tabel }}$ 0,1966. Sehingga data kuesioner dalam penelitian ini valid.

\section{Uji Reliabilitas}

Berdasarkan hasil uji reliabilitas menunjukkan bahwa nilai cronbach's alpha dari semua variabel lebih besar dari 0,60. Sehingga data dalam penelitian ini reliabel.

\section{Uji Normalitas}

Dari uji normalitas menghasilkan nilai asymptotic significance sebesar 0,954 lebih besar dari 0,05 atau 5\%, sehingga variabel pengganggu atau residual memiliki distribusi normal. Dengan demikian model regresi layak digunakan untuk melakukan penelitian.

\section{Uji Multikolonieritas}

Hasil perhitungan uji multikolinieritas menunjukkan bahwa semua variabel memiliki nilai Tolerance $\geq 0,10$ dan nilai $\mathrm{VIF} \leq 10$. Hal ini menunjukkan tidak ada multikolinieritas antar variabel independen dalam model regresi.

\section{Uji Heteroskedastisitas}

Berdasarkan uji heteroskedastisitas dengan jelas menunjukkan bahwa tidak ada satupun variabel independen yang signifikan secara statistik mempengaruhi variabel dependen nilai Absolut Res (ABS_RES). Hal ini terlihat dari probabilitas signifikansi diatas 5\% atau 0,05. Jadi dapat disimpulkan model regresi tidak terdapat heteroskedastisitas.

\section{Uji Autokorelasi}

Berdasarkan uji autokorelasi diperoleh persamaan: 1,8031 (du) $<2,002$ (DW) $<2,1969$ (4-du). Dari persamaan tersebut maka dapat disimpulkan bahwa tidak ada autokorelasi positif dan negatif, artinya tidak terdapat autokeralasi pada model regresi ini.

\section{Hasil Uji F (Simultan)}

Hasil uji F menunjukkan bahwa secara bersama-sama variabel persepsi manfaat, persepsi kemudahan penggunaan, dan persepsi resiko berpengaruh positif dan signifikan terhadap minat mengunakan internet banking pada Bank Jateng Kantor Cabang Pembantu Kaligawe. Halini terjadi karena dari hasil uji $\mathrm{F}$ menunjukkan bahwa $\mathrm{F}_{\text {hitung }} 108,320$ lebih besar dari $\mathrm{F}_{\text {tabel }} 2,20$ 
atau nilai signifikansi 0,000 lebih kecil dari 0,05. Berdasarkan hasil uji $\mathrm{F}$ ini, dapat diambil kesimpulan bahwa hipotesis 1 dinyatakan diterima.

\section{Uji t (Parsial)}

Berdasarkan hasil pengujian uji t, diperoleh nilai thitung dari enam variabel independen yaitu variabel ability, attitude, appearance, attention, action dan accountability masing-masing dengan nilai $t_{\text {hitung }} 3,666 ; 2,601 ; 2,259 ; 3,215 ; 5,268$ dan 3,880 lebih besar dari $t_{\text {tabel }} 1,98580$. Hal ini menunjukkan bahwa hipotesis 2, hipotesis 3, hipotesis 4, hipotesis 5, hipotesis 6 , hipotesis 7 dinyatakan diterima.

\section{Uji Koefisien Determinasi $\left(\mathbf{R}^{2}\right)$}

Besarnya nilai koefisien determinasi (Adjusted $R^{2}$ ) dalam penelitian ini sebesar 0,867 . Hal ini menunjukkan bahwa variabel persepsi manfaat, persepsi kemudahan penggunaan, dan persepsi risiko dalam menjelaskan minat penggunaan internet banking sebesar $86,7 \%$ dan sisanya 13,3\% dipengaruhi oleh variabel lain yang tidak diteliti dalam penelitian ini.

\section{PENUTUP}

\section{Kesimpulan}

Berdasarkan hasil pengujian statistik untuk menguji pengaruh dimensi pelayanan prima terhadap kepuasan nasabah tabungan pada PT Bank Rakyat Indonesia (Persero) Tbk. Kantor Cabang Kendal, maka peneliti dapat mengambil kesimpulan sebagai berikut:

1. Pelayanan prima yang meliputi kemampuan (ability), sikap (attitude), penampilan (appearance), perhatian (attention), tindakan (action), dan tanggung jawab (accountability) secara simultan berpengaruh signifikan terhadap kepuasan nasabah tabungan pada PT Bank Rakyat Indonesia (Persero) Tbk. Kantor Cabang Kendal.

2. Variabel kemampuan (ability), mempunyai pengaruh yang signifikan terhadap kepuasan nasabah tabungan pada PT Bank Rakyat Indonesia (Persero) Tbk. Kantor Cabang Kendal.

3. Variabel sikap (attitude), mempunyai pengaruh yang signifikan terhadap kepuasan nasabah tabungan pada PT Bank Rakyat Indonesia (Persero) Tbk. Kantor Cabang Kendal.

4. Variabel penampilan (appearance), mempunyai pengaruh yang signifikan terhadap kepuasan nasabah tabungan pada PT Bank Rakyat Indonesia (Persero) Tbk. Kantor Cabang Kendal. 
5. Variabel perhatian (attention), mempunyai pengaruh yang signifikan terhadap kepuasan nasabah tabungan pada PT Bank Rakyat Indonesia (Persero) Tbk. Kantor Cabang Kendal.

6. Variabel tindakan (action), mempunyai pengaruh yang signifikan terhadap kepuasan nasabah tabungan pada PT Bank Rakyat Indonesia (Persero) Tbk. Kantor Cabang Kendal.

7. Variabel tanggung jawab (accountability), mempunyai pengaruh yang signifikan terhadap kepuasan nasabah tabungan pada PT Bank Rakyat Indonesia (Persero) Tbk. Kantor Cabang Kendal.

\section{Impliasi Teoritis}

Implikasi teoritis dalam penelitian ini dikembangkan untuk memperkuat dukungan atas beberapa penelitian terdahulu. Variabel ability, attitude, appearance, attention, dan action masing - masing berpengaruh signifikan terhadap kepuasan nasabah tabungan pada PT Bank Rakyat Indonesia (Persero) Tbk. Kantor Cabang Kendal. Hasil penelitian ini sejalan dengan hasil penelitian terdahulu yang dilakukan oleh Silvester Kukuh (2009), Widjojo dan Suardy (2009), Yesi N et al., (2013), Moyu dan Soesiantoro (2015) serta Putri Sayekti (2017).

\section{Implikasi Manajerial}

Implikasi manajerial ini dapat digunakan sebagai masukan pada PT Bank Rakyat Indonesia (Persero) Tbk. Kantor Cabang Kendal dalam hal meningkatkan kepuasan nasabah tabungan. Untuk meningkatkan pelayanan prima yang mampu meningkatkan kepuasan nasabah tabungan pada PT Bank Rakyat Indonesia (Persero) Tbk. Kantor Cabang Kendal perlu mengetahui variabel yang dominan berdasarkan signifikansinya adalah sebagai berikut:

1. Variabel tindakan (action) merupakan variabel yang mempunyai pengaruh signifikan terbesar dalam membentuk kepuasan nasabah tabungan pada PT Bank Rakyat Indonesia (Persero) Tbk. Kantor Cabang Kendal. Oleh karena itu, pihak manajemen PT Bank Rakyat Indonesia (Persero) Tbk. Kantor Cabang Kendal diharapkan karyawan dapat senantiasa merespon keluhan nasabah, bekerja dengan teliti, memberikan layanan yang cepat kepada nasabah, dan memberikan informasi terbaru kepada nasabah.

2. Variabel tanggung jawab (accountability) merupakan variabel yang mempunyai pengaruh signifikan urutan kedua dalam membentuk kepuasan nasabah tabungan pada PT Bank Rakyat Indonesia (Persero) Tbk. Kantor Cabang Kendal. Oleh karena itu, pihak manajemen PT Bank Rakyat Indonesia (Persero) Tbk. Kantor Cabang Kendal diharapkan karyawan dapat memberikan solusi atas permasalahan yang dihadapi oleh nasabah, 
memberikan kemudahan prosedur pelayanan kepada nasabah, berusaha tidak melakukan kesalahan kepada nasabah, dan menyelesaikan keluhan yang dihadapi oleh nasabah.

3. Variabel kemampuan (ability) merupakan variabel yang mempunyai pengaruh signifikan urutan ketiga dalam membentuk kepuasan nasabah tabungan pada PT Bank Rakyat Indonesia (Persero) Tbk. Kantor Cabang Kendal. Oleh karena itu, pihak manajemen PT Bank Rakyat Indonesia (Persero) Tbk. Kantor Cabang Kendal diharapkan karyawan dapat memiliki kemampuan dalam melayani nasabah, memiliki kemampuan berkomunikasi yang baik dengan nasabah, dan memiliki kemampuan dalam menjaga hubungan baik dengan nasabah.

4. Variabel perhatian (attention) merupakan variabel yang mempunyai pengaruh signifikan urutan keempat dalam membentuk kepuasan nasabah tabungan pada PT Bank Rakyat Indonesia (Persero) Tbk. Kantor Cabang Kendal. Oleh karena itu, pihak manajemen PT Bank Rakyat Indonesia (Persero) Tbk. Kantor Cabang Kendal diharapkan karyawan dapat mengatasi kebutuhan yang dialami oleh nasabah, memberikan perhatian yang luwes dalam membimbing nasabah, meluangkan waktu menanggapi permintaan nasabah, menerima saran yang diberikan nasabah, dan menerima kritik yang diberikan nasabah.

5. Variabel sikap (attitude) merupakan variabel yang mempunyai pengaruh signifikan urutan kelima membentuk kepuasan nasabah tabungan pada PT Bank Rakyat Indonesia (Persero) Tbk. Kantor Cabang Kendal. Oleh karena itu, pihak manajemen PT Bank Rakyat Indonesia (Persero) Tbk. Kantor Cabang Kendal diharapkan karyawan dapat bersikap ramah terhadap nasabah, bersikap sopan terhadap nasabah, bersikap lebih sabar terhadap nasabah, dan bersikap menghormati yang di tunjukkan terhadap nasabah baik yang tua maupun yang muda.

6. Variabel penampilan (appearance) merupakan variabel yang mempunyai pengaruh signifikan urutan terkecil atau keenam membentuk kepuasan nasabah tabungan pada PT Bank Rakyat Indonesia (Persero) Tbk. Kantor Cabang Kendal. Oleh karena itu, pihak manajemen PT Bank Rakyat Indonesia (Persero) Tbk. Kantor Cabang Kendal diharapkan karyawan dapat berpenampilan menarik saat bekerja meskipun pada jam-jam kerja siang menjelang sore dan berpenampilan rapi dan bersih saat bekerja dengan cara selalu merapikan tempat kerja ketika melihat tempat kerja tidak rapi. 


\section{Keterbatasan Penelitian}

Objek pada penelitian ini terbatas hanya pada PT Bank Rakyat Indonesia (Persero) Tbk. Kantor Cabang Kendal dengan kriteria sampel tertentu. Diharapkan pada penelitian mendatang memperluas sampel dengan memperluas objek penelitian tidak hanya pada satu bank saja.

Dalam penelitian ini hanya meneliti variabel pelayanan prima yaitu ability, attitude, appearance, attention, action, dan accountability. Diharapkan pada penelitian mendatang menambah variabel lain agar mendapat pengaruh variabel yang lebih besar seperti kenyamanan (comfortness) dari penelitian Novia Khairun Lupus (2017) hal ini akan sangat bermanfaat bagi peneliti selanjutnya sebagai referensi dalam penelitian.

\section{DAFTAR PUSTAKA}

Bank Indonesia. 1998. Undang-Undang Republika Indonesia Nomor 10 Tahun 1998 Tentang Perbankan. Jakarta: Bank Indonesia.

Barata, Atep Adya. 2003. Dasar-dasar Pelayanan Prima. Jakarta: Alex Media Komputindo.

Duriany, Embun. 2011. Etika Pelayanan Jasa. Semarang: Politeknik Negeri Semarang.

Fadilah, Nur Yesi, Mochamad Choiri, dan Rahmi Yuniarti. 2013. Analisis Pengaruh Faktor Pelayanan Prima (Service Excelent) Terhadap Kepuasan Wajib Pajak (Studi Kasus di Kantor Palayanan Pajak Pratama Malang Utara). Jurnal Rekayasa dan Manajemen Sistem Industri. Volume 1, Nomor 2.

Ferdinand, Agusty. 2006. Metode Penelitian Manajemen. Fakultas Ekonomika dan Bisnis. Universitas Diponegoro.

Ghozali, Imam. 2006. Aplikasi Analisis Multivariate dengan Program SPSS. Semarang: Badan Penerbit Universitas Diponegoro.

Ghozali, Imam. 2018. Aplikasi Analisis Multivariate dengan Program SPSS. Semarang: Badan Penerbit Universitas Diponegoro.

Herdiansyah, Haris. 2010. Metodologi Penelitian Kualitatif untuk Ilmu-ilmu Sosial. Jakarta: Salemba Humanika.

https://bri.co.id/. Diunduh tanggal 10 Januari 2019.

Ikatan Bankir Indonesia. 2014. Mengelola Kualitas Layanan Perbankan. Jakarta: PT.Gramedia Pustaka Utama.

Infobank. 2018. The Best Bank Service Excellent 2018. Vol. XL, No. 478 Mei 2018.

Kasmir. 2011. Etika Customer Service. Jakarta: PT Raja Grafindo Persada.

Kasmir. 2012. Dasar-dasar Perbankan. Jakarta: PT Raja Grafindo Persada. 
Kukuh, Silvester. 2009. Pengaruh Variabel Pelayanan Prima Terhadap Kepuasan Konsumen (Studi Kasus pada Bank Negara Indonesia Cabang Jalan Margonda Raya). Jurnal. Depok: Universitas Gunadarma.

Margono, S. 2010. Metodologi Penelitian Pendidikan. Jakarta: PT. Rineka Cipta.

Marzuki. 2000. Metodologi Riset. Yogyakarta: Badan Penerbit Fakultas Ekonomi Universitas Islam Indonesia.

Moyu, Edwin Erut, dan Adi Soesiantoro. 2015. Analisis Penerapan Pelayanan Prima Terhadap Kepuasan Masyarakat (Studi Kasus pada Kantor Kelurahan Nginden Jangkungan, Surabaya). Jurnal JPAP. Volume 1, Nomor 01.

Pra Survey 2019. Kendal: PT Bank Rakyat Indonesia (Persero) Tbk. Kantor Cabang Kendal. Sayekti, Putri. 2017. Pengaruh Pelayanan Prima Terhadap Kepuasan Satuan Kerja Di Lingkup Kantor Pelayanan Perbendaharaan Negara Bandung I. Jurnal . Volume XIV, Nomor 02. Rangkuti, Freddy. 2003. Measuring Customer Satisfaction:Gaining Customer Relationship Strategy Teknik Mengukur dan Strategi Meningkatkan Kepuasan Pelanggan \& Analisis Kasus PLN- JP. Jakarta: PT Gramedia Pustaka Utama.

Sarjono, Haryadi dan Winda Julianita. 2011. SPSS vs LISREL: Sebuah Pengantar Aplikasi untuk Riset. Jakarta: Salemba Empat.

Sinamora, Bilson. 2004. Riset Pemasaran. Jakarta: PT Gramedia Pustaka Utama.

Sugiyono. 2007. Metode Penelitian Kuantitatif Kualitatif dan R\&D. Bandung: ALFABETA.

Sugiyono. 2016. Statistika Untuk Penelitian. Bandung: ALFABETA.

Sulistyorini, Utami Tri. 2006. Strategi Pemasaran Jasa pada Lembaga Keuangan. Semarang: BPPP Politeknik Negeri Semarang.

Sulistyorini, Utami Tri. 2018. Metode Penelitian Analisis Kausal-Regresi. Semarang: BPPP Politeknik Negeri Semarang.

Supardi. 2005. Metodologi Penelitian Ekonomi \& Bisnis. Yogyakarta: UII Press

Tim Penyusun Pedoman Tugas Akhir 2014. Pedoman Penyusunan Tugas Akhir Jurusan Akuntansi Politeknik Negeri Semarang. Semarang: Politeknik Negeri Semarang.

Tjiptono, Fandy. 2004. Manajemen Jasa. Yogyakarta: Andi Yogyakarta.

Umar, Husein. 2003. Metode Riset Perilaku Konsumen Jasa. Jakarta: Ghalia Indonesia.

Widjojo, Adi S, dan Weman Suardy. 2009. Analisis Strategi Pelayanan Oleh Front Liner dan Pengaruhnya Terhadap Kepuasan Nasabah pada PT. Bank Central Asia Tbk. Capen Mayor Oking. Jurnal Ilmiah Kesatuan. Volume 11, Nomor 2 . 